See Article page e333.

\section{Commentary: Just shy of a bullseye!}

\author{
Les James, MD, MPH, and Eugene A. Grossi, MD
}

In this paper, Kono and colleagues ${ }^{1}$ created a tour de force rat model of ischemic cardiomyopathy with independently surgically induced mitral regurgitation (MR) to study the early and late effects of MR on left ventricle (LV) remodeling. Myocardial infarction (MI) was created by left coronary artery ligation, then either early or late severe MR was introduced at 4 or 10 weeks, respectively. Rats with MI only were used as controls. At 20 weeks from the index procedure, both end-diastolic volume and end-systolic volume were significantly larger in the groups with MR. In the MI-only group, maximal LV remodeling was observed until 6 weeks, after which point it plateaued. Conversely, in those with surgically induced MR, LV remodeling was increased and persisted for the duration of the study. From these results, the authors draw the conclusion that postinfarction MR, regardless of the timing of its onset, leads to adverse LV remodeling.

We congratulate the authors on a well-posed question and an elegant study design. The model, while exceptionally executed, was underused in that it did not sufficiently explore the regional histopathology in the injured, normal, and borderline areas of the myocardium.

A 2011 study from Soleimani and colleagues ${ }^{2}$ from the University of California at San Francisco demonstrated that MR accelerates LV remodeling after MI, although it was unclear to what extent MR contributed to fiber and cross-fiber stress in the border zone and remote

\footnotetext{
From the Department of Cardiothoracic Surgery, NYU Grossman School of Medicine, New York, NY.

Disclosures: Dr Grossi has intellectual property and receives royalties from Medtronic for valve repair devices and has intellectual property and receives royalties from Edwards Lifesciences. Dr James has reported no conflicts of interest.

The Journal policy requires editors and reviewers to disclose conflicts of interest and to decline handling or reviewing manuscripts for which they may have a conflict of interest. The editors and reviewers of this article have no conflicts of interest.

Received for publication Nov 29, 2021; revisions received Nov 29, 2021; accepted for publication Nov 30, 2021; available ahead of print Dec 3, 2021.

Address for reprints: Eugene A. Grossi, MD, Department of Cardiothoracic Surgery, NYU Grossman School of Medicine, 530 First Ave, Suite 9V, Skirball Building,

New York, NY 10016 (E-mail: Eugene.Grossi@nyulangone.org).

J Thorac Cardiovasc Surg 2022;164:e349

$0022-5223 / \$ 36.00$

Copyright (c) 2021 by The American Association for Thoracic Surgery

https://doi.org/10.1016/j.jtcvs.2021.11.069
}

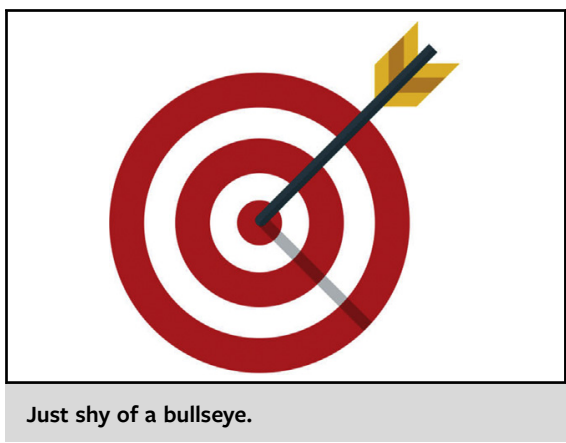

CENTRAL MESSAGE

An exceptionally well-designed model studying effects of MR on LV remodeling may be further used to understand the pathophysiologic processes at work in remote areas of the

myocardium of myocardium. the LV.

Decreased contractility in the nonischemic border zone surrounding a $\mathrm{MI}$ is due in part to degradation of cardiomyocyte sarcomere components by intracellular matrix metalloproteinase-2. In addition, Schwarz and colleagues ${ }^{3}$ had shown previously that apoptotic markers are activated in the surviving myocardium remote from the infarct area as early as 1 day after MI and persist for up to 4 weeks. Work by Spaulding and colleagues ${ }^{4}$ published in 2018 showed that treatment with doxycycline in the post-MI period had the immediate and sustained effect of normalizing matrix metalloproteinase2 levels, leading to increased wall thickness at end-systole and improved contractility in the border zone. ${ }^{4}$

In this study by Kono and colleagues, ${ }^{1}$ the authors focused their investigative efforts on the effect of early and late MR on LV remodeling. While this is important, there was a missed opportunity to measure biomarkers in remote and border zones, which would have yielded an improved understanding of the pathophysiologic processes occurring in these regions.

The authors have given us an excellent model with compelling results. Might preserved tissue hold these answers? Additional investigation into processes at the cellular level in remote and border zones might elucidate possibilities for future interventional therapies and that would hit the bullseye. 


\section{References}

1. Kono T, Onohara D, Amedi A, Corporan D, Padala M. Effect of early versus late onset mitral regurgitation on left ventricular remodeling in ischemic cardiomyopathy in an animal model. J Thorac Cardiovasc Surg. 2022;164: e333-47.

2. Soleimani M, Khazalpour M, Cheng G, Zhang Z, Acevedo-Bolton G, Saloner DA, et al. Moderate mitral regurgitation accelerates left ventricular re- modeling after posterolateral myocardial infarction. Ann Thorac Surg. 2011; 92:1614-20.

3. Schwarz K, Simonis G, Yu X, Wiedemann S, Strasser RH. Apoptosis at a distance: remote activation of caspase- 3 occurs early after myocardial infarction. Mol Cell Biochem. 2006;281:45-54.

4. Spaulding K, Takaba K, Collins A, Faraji F, Wang G, Aguayo E, et al. Short term doxycycline treatment induces sustained improvement in myocardial infarction border zone contractility. PLoS One. 2018;13:e0192720.
See Article page e333.

\section{Commentary: To screen or not to screen? That is the question-}

\section{Stephen H. McKellar, MD, MSc}

Of all the memorable lines in William Shakespeare's Hamlet, perhaps the most famous one, is "To be, or not to be? That is the question." 2 For purposes of commenting on this article, perhaps it can be modified to "To screen, or not to screen? That is the question" and applied to this innovative preclinical study of myocardial infarction (MI) and mitral regurgitation (MR) by Kono and colleagues ${ }^{3}$ in this issue of the Journal.

In their elegant animal study, the authors attempt to answer the question whether early or late MR has a greater impact on left ventricular remodeling following MI. They induced $\mathrm{MI}$ in rats with coronary artery ligation and then randomized them to 1 of 3 groups: MI alone, MI + early MR, or MI + late MR. The authors observed significantly worse left ventricular remodeling in the $2 \mathrm{MI}+$ MR groups compared with the MI-alone group, with no differences between the early and late MR groups. The authors conclude that MR has a strong impact on remodeling, regardless of whether it appears early or late, following MI.

This observation has important clinical implications with respect to screening for MR following MI, as it appears any

\footnotetext{
From the Division of Cardiovascular and Thoracic Surgery, Intermountain Medical Center, Murray, Utah.

Disclosures: The author reported no conflicts of interest.

The Journal policy requires editors and reviewers to disclose conflicts of interest and to decline handling or reviewing manuscripts for which they may have a conflict of interest. The editors and reviewers of this article have no conflicts of interest.

Received for publication Nov 17, 2021; revisions received Nov 17, 2021; accepted for publication Nov 19, 2021; available ahead of print Nov 24, 2021.

Address for reprints: Stephen H. McKellar, MD, MSc, Division of Cardiovascular and Thoracic Surgery, Intermountain Medical Center, Eccles Outpatient Center, 5169 Cottonwood St, Suite 600, Murray, UT 84107 (E-mail: stephen.mckellar@imail. org).

J Thorac Cardiovasc Surg 2022;164:e350-1

$0022-5223 / \$ 36.00$

Copyright (c) 2021 by The American Association for Thoracic Surgery

https://doi.org/10.1016/j.jtcvs.2021.11.045
}

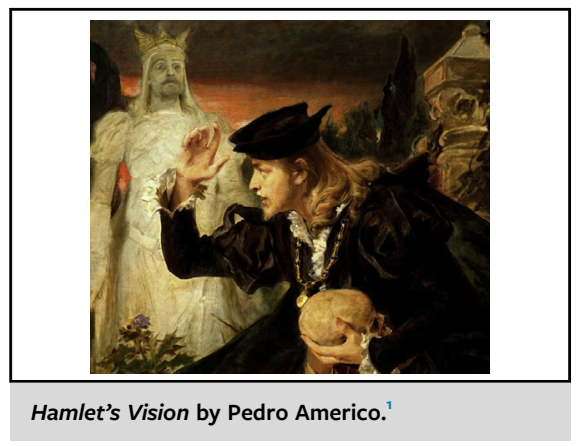

CENTRAL MESSAGE

Mitral regurgitation adversely

impacts left ventricular remod-

eling regardless of whether it

appears early or late following

myocardial infarction.

MR, early- or late-onset, is clinically relevant. This then begs a host of questions as to how often patients should be screened with echocardiography for the development of MR following MI. Once found, which severities of MR require intervention? Should standard quantitative indications for MR be applied in the patient after MI, or is there a role for earlier intervention, given the risk of adverse remodeling? Finally, should surgical or transcatheter repair should be used for patients who develop MR even if there isn't concomitant pathology be corrected if early intervention is warranted?

The relationship between MR and MI has long been and continues to be an area rife with unanswered questions. Clearly, there is much we don't know about the interaction between ischemic heart disease, MR, and reverse ventricular remodeling. This preclinical study adds insights into the temporal relationships between these entities and pushes the field toward additional questions to be studied and answered. 